\title{
APLIKASI PENGELOLAAN SURAT ELEKTRONIK BERBASIS WEB PADA PKBM PAJA MANDIRI TANGERANG
}

\author{
Arief Herdiansah $^{1}$, Yani Sugiyani ${ }^{2}$, Syepry Maulana Husein ${ }^{3}$, Alifah ${ }^{4}$ \\ Universitas Muhammadiyah Tangerang, $\mathbf{1 , 2 , 3 , 4}$ \\ Email : $\underline{\text { arief_herdiansah@umt.ac.id }{ }^{1}, \text { yani.sugiyani@ft-umt.ac.id }{ }^{2}}$, syepry.mulana@ft-umt.ac.id ${ }^{3}$, \\ alifahhumairah50@gmail.com ${ }^{4}$
}

\begin{tabular}{|c|c|}
\hline Received: & Published : \\
\hline & $\begin{array}{l}\text { Abstract } \\
\text { Paja Mandiri Community Learning Activity Center (PKBM) is an LSM (Non-Governmental } \\
\text { Organization) engaged in non-formal education. In the operational activities of the teaching and } \\
\text { learning process at PKBM Paja Mandiri, of course it cannot be separated from the process of managing } \\
\text { incoming and outgoing letters and other supporting documents. The method of community service } \\
\text { activities that the researchers conducted was observation and interviews with several staff at PKBM } \\
\text { Paja Mandiri and the results found information that currently the process of handling and managing } \\
\text { incoming mail, outgoing mail and other documents is still carried out conventionally. The problems } \\
\text { that occur include, it takes a long time to retrieve the documents that have been stored, because of the } \\
\text { miss place the document. Therefore, the researcher tries to design an e-filing application (electronic } \\
\text { filing) using UML and develops it using the PHP programming language. This research has produced } \\
\text { an e-filing system that can be used to assist the management of incoming and outgoing mail in PKBM } \\
\text { Paja Mandiri Tangerang. }\end{array}$ \\
\hline
\end{tabular}

Keywords: Letters, electronic filing, PKBM, NGOs.

\begin{abstract}
Abstrak
Pusat Kegiatan Belajar Masyarakat (PKBM) Paja Mandiri merupakan salah satu LSM (Lembaga Swadaya Masyarakat) yang bergerak dibidang Pendidikan non-formal. Dalam operasional aktifitas proses belajar mengajar di PKBM Paja Mandiri tentunya tidak terlepas pada proses pengelolaan surat masuk dan surat keluar serta dokumen pendukung lainnya. Metode aktifitas pengabdian yang peneliti lakukan adaah dengan observasi dan wawancara dengan beberapa staf di PKBM Paja Mandiri dan hasilnya ditemukan informasi bahwa saat ini proses penanganan dan pengelolaan surat masuk, surat keluar dan dokumen lainnya masih dilakukan secara konvensional. Permasalahan yang terjadi antara lain, dibutuhkan waktu yang cukup lama untuk menemukan kembali dokumen yan telah disimpan, karena permasalahan salah dalam penempatan dokumen tersebut. Oleh karena itu peneliti mencoba merancang aplikasi e-filing (pengarsipan secara elektronik) mengunakan UML dan mengembangkannya menggunakan bahasa pemrograman PHP. Penelitian ini telah menghasilkan sebuah sistem $e$-filing yang dapat digunakan untuk membantu pengelolaan surat masuk dan surat keluar di PKBM Paja Mandiri Tangerang.
\end{abstract}

Kata kunci : Surat, Pengarsipan elektronik, PKBM, LSM

\section{To cite this article:}

Herdiansah. (2021). Aplikasi Pengelolaan Surat Elektronik Berbasis Web pada PKBM Paja Mandiri Tangerang. Journal of Technology and Social for Community Service (JTSCS), Vol(1) 


\section{PENDAHULUAN}

Pusat Kegiatan Belajar Masyarakat (PKBM) adalah sebuah Lembaga swadaya masyarakat (LSM) yang bergerak dalam bidang pendidikan. Aktifitas yang dilakukan PKBM salah satunya adalah membantu pemerintah dalam memberikan hak belajar kepada masyarakat. Pendidikan merupakan salah satu usaha untuk menyiapkan peserta didik melalui kegiatan bimbingan, pengajaran atau pembelajaran, dan atau latihan bagi perananya di masa yang akan datang. Penelitian yang peneliti lakukan adalah membantu salah satu PKBM yang ada di Tangerang yaitu PKBM Paja Mandiri untuk dapat melakukan penglolaan surat dan dokumen operasional yang ada di PKBM dengan memanfaat teknologi informasi. Saat ini aktifitas yang dilakukan PKBM Paja Mandiri termasuk dalam aktifitas pendidikan nonformal, sebagaimana yang terdapat dalam UU No.20 Tahun 2003 tentang sistem pendidikan nasional, pendidikan nonformal itu meliputi kelompok belajar, kursus-kursus, pelatihan, majelis ta'lim, pusat kegiatan belajar masyarakat, dan satuan pendidikan yang sejenis. Pendidikan nonformal, merupakan salah satu jenis pendidikan yang memilki keterkaitan dengan pendidikan sepanjang hayat, di mana keduanya memilki tujuan yang sama, yaitu untuk bertahan hidup dan mempertahankan kehidupannya, serta untuk meningkatkan kualitas hidup.

Tema pengabdian masyarakat tentang pengelolaan surat elektronik peneliti ambil setelah peneliti melakukan observasi dan wawancana dengan pengurus PKBM Paja Mandiri, dan ditemukan informasi bahwa saat ini di lembaga pendidikan nonformal PKBM Paja Mandiri Tangerang proses penanganan dan pengelolaan surat masih konvensional, yaitu menggunakan pencatatan secara manual dan surat disimpan dalam lemari-lemari yang ada di PKBM Paja Mandiri. Penyimpanan surat dan arsip dengan cara manual seperti itu sangat besar terjadi kehilangan data atau rusaknya surat tersebut karena pada dasarnya pengelolaan surat dan arsip dalam bentuk fisik membutuhkan tempat penyimpanan yang memadai dan tata cara pemeliharaan yang sesuai agar surat yang dalam bentuk kertas tersebut tidak mudah rusak.

Keluaran dari hasil pengabdian masyarakat yang peneliti lakukan adalah sebuah rancangan dan hasil pengembangan surat elektronik yaitu sebuah aplikasi pengelolaan surat secara digital, yang diharapkan dapat meningkatkan sistem pengolahan surat menjadi sistem yang terkomputerisasi dimana komputer sebagai alat bantu dalam menyelesaikan tugas-tugas yang berkaitan dengan pengarsipan dokumen, sehingga setiap pekerjaan dapat diselesaikan dengan efektif dan efisien.

\section{TELAAH PUSTAKA}

\section{A. Pusat Kegiatan Belajar Masyarakat}

Pusat Kegiatan Belajar Masyarakat (PKBM) adalah sebuah lembaga pendidikan yang diselenggarakan di luar sistem pendidikan non formal diarahkan untuk masyarakat pedesaan dan perkotaan dengan dikelolah oleh masyarakat itu sendiri serta memberi kesempatan kepada mereka untuk mengembangkan berbagai model pembelajaran dengan tujuan mengembangkan berbagai model pembelajaran dengan tujuan mengembangkan kemampuan dan keterampilan masyarakat agar mampu meningkatkan kualitas hidupnya (Mustofa, 2010). Pengembangan konsep PKBM haruslah memperhatikan dua faktor secara bersamaan yaitu faktor kemampun konsep dalam menjelaskan secara lengkap dan utuh seluruh eksistensi dan karakteristik PKBM itu sendiri dan faktor kemampuan konsep dalam mengakomodasikan berbagai perkembangan dan keragaman PKBM baik yang telah ada maupun yang akan datang. Atas dasar pertimbangan tersebut maka konsep PKBM yang diuraikan dalam kesempatan ini lebih merupakan konsep yang bersifat generik. Artinya konsep PKBM yang diungkapkan ini adalah konsep yang dapat dikembangkan lebih lanjut ke dalam berbagai model-model PKBM yang bervariasi

Tujuan pendidikan nonformal adalah memberikan pendidikan dalam jangka waktu yang sangat singkat yang berorientasi pada bidang keterampilan khusus ynag dikemas dalam bentuk paket-paket berdasarkan kebutuhan masyarakat. PKBM didirikan, diselenggarakan dan dikelola oleh masyarakat dan merupakan mitra pemerintah dalam meningkatkan kualitas Sumber Daya Manusia (Ayub et al., 2014).

\section{B. Sistem Informasi dan Manajemen Sistem Informasi}

Sistem merupakan sebuah jaringan prosedur yang dirancang menurut pola terpadudalam rangka mendukung dan melaksanakan kegiatan pokok perusahaan (Handayani et al., 2020). Sistem merupakan seperangkat elemen yang saling bergantung yang bersama-sama mencapai tujuan tertentu. Dimana sistem harus memiliki organisasi, hubungan timbal balik, integrasi dan tujuan pokok (Gelinas, J.U; Dull, Richard B; Wheeler, 2012). 
Informasi adalah data yang telah dikelola dan diproses untuk memberikan arti dan memperbaiki proses pengambilan keputusan. Sebagaimana perannya, pengguna membuat keputusan yang lebih baik sebagai kuantitas dan kualitas dari peningkatan informasi (Romney \& Steinbart, 2011).

Sistem dan sistem informasi adalah suatu hal yang saling berhubungan satu dengan lainnya yang akhirnya menghasilkan sebuah informasi/data yang berguna bagi orang yang dituju sesuai dengan peruntukannya (Herdiansah, 2020).

Manajemen sistem informasi yang baik berhubungan erat dengan pengolahan data yang baik, karena pengolahan data yang masih belum terkomputerisasi dengan baik akan menghasilkan kualitas informasi yang kurang akurat (Fitriawati et al., 2019).

\section{B. Arsip dan Arsip Elektronik}

Menurut Undang-undang nomor 43 tahun 2009 tentang kearsipan, arsip adalah rekaman kegiatan atau peristiwa dalam berbagai bentuk dan media sesuai dengan perkembangan teknologi informasi dan komunikasi yang dibuat dan diterima oleh lembaga negara, pemerintahan daerah, lembaga pendidikan, perusahaan, organisasi politik, organisasi kemasyarakatan, dan perseorangan dalam pelaksanaan kehidupan bermasyarakat, berbangsa, dan bernegara.

Sebuah dokumen dalam bentuk kertas dikatakan sebagai sebuah arsip jika dokumen tersebutdibuat oleh orang yang memang memiliki wewenang, kemudian diberikan kepada orang yang memang berhak menerima dokumen tersebut dan menimbulkan nilai guna bagi penerima dokumen tersebut.

Arsip elektronik adalah kumpulan data yang tersimpan dalam bentuk data hasil pemindaian (scan) yang dipindahkan secara elektronik atau dilakukan dengan digital copy menggunakan resolusi tinggi, kemudian disimpan dalam hard drive atau optical disk (Utari D \& Wibowo, 2013).

Arsip digital adalah arsip yang telah dialih mediakan menjadi format digital (softcopy) dan telah melalui tahapan prosedur proses alih media sebagai mana dijabarkan dalam Peraturan Pemerintah no 28 tahun 2012 tentang pelaksanaan undang-undang no 43 tahun 2009 tentang kearsipan (ANRI, 2015).

Dokumen/arsip elektronik dapat dikatakan juga sebagai suatu kumpulan data (dokumen/arsip) yang telah dikonversikan menjadi bentuk digital dan secara sengaja disimpan dalam format digital serta dikelola dengan bantuan aplikasi berbasis komputer.

\section{METODE PELAKSANAAN Tempat dan Waktu}

Penelitian dilakukan di Pusat Kegiatan Belajar Masyarakat (PKBM) Paja Mandiri Tangerang yang merupakan lembaga pendidikan non-formal yang beralamat di Blok D 10, J1. Taman Kutabumi No.34, Kutabumi, Kec. Ps. Kemis, Tangerang, Banten 15561. PKBM Paja Mandiri dibentuk pada tanggal 1 Desember 1997 dan kemudian diresmikan tanggal 5 Mei 1999 oleh Bidang Dikmas Kanwil Depdikmas Provinsi Jawa Barat. PKBM Paja mandiri didirikan barsama oleh masyarakat dibawah Yayasan Paja Mandiri.

Penelitian ini perancangan dan pengembangan aplikasi e-filing dilakukan sejak bulan 1 September 2020 sampai dengan 20 November 2020 dan proses sosialisasi pengunaan aplikasi e-filing di PKBM Paja mandiri dilakukan bulan Desember 2020 dan Maret 2021.

\section{Khalayak Sasaran}

Sasarannya adalah PKBM Paja mandiri, dan tujuannya adalah membantu PKBM Paja Mandiri mewujudkan visi-nya untuk mengembangkan setiap insan yang berkualitas dan berkehidupan yang lebih tinggi melalui peningkatan Sumber Daya Manusia (SDM).

\section{Teknik Pengumpulan Data}

Metode pengumpulan data berupa suatu pernyataan tentang sifat, keadaan, kegiatan tertentu dan sejenisnya. Pengumpulan data dilakukan untuk mendapatkan suatu informasi yang dibutuhkan dalam mencapai tujuan penelitian. Metode pengumpulan data yang digunakan dalam penelitian adalah metode campuran dimana dilakukan pengumpulan data dengan cara melakukan observasi dan melakukan wawancara/ intervivew. 


\section{HASIL DAN PEMBAHASAN}

A. Use Case Diagram

Use Case merupakan pemodelan untuk kegiatan pada sistem yang akan dibuat. Sistem memiliki 3 aktor yaitu Admin, Staff Tata Usaha dan Ketua PKBM. Use case diagram:

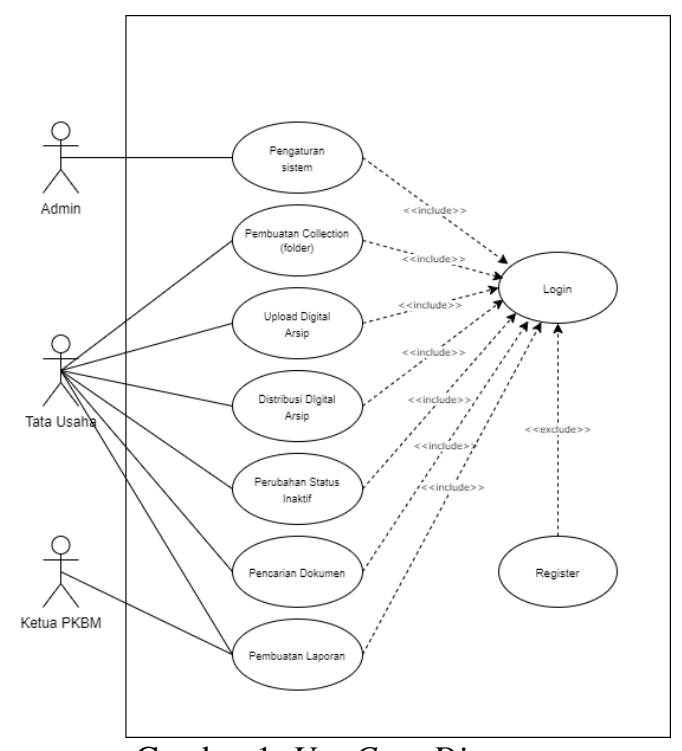

Gambar 1. Use Case Diagram

\section{B. Class Diagram}

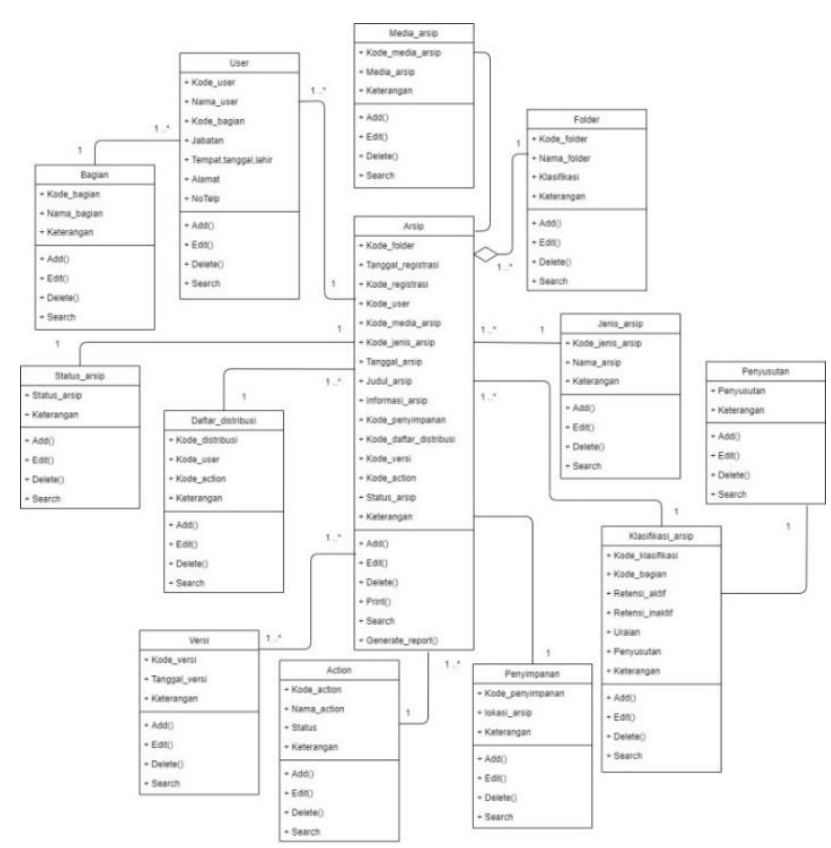

Gambar 2. Class Diagram 


\section{Implementasi Tampilan Login}

Implementasi login merupakan tampilan yang digunakan sebagai sebagai hak akses pengguna ke halaman menu utama, berikut tampilan login pada gambar 3 dibawah ini :

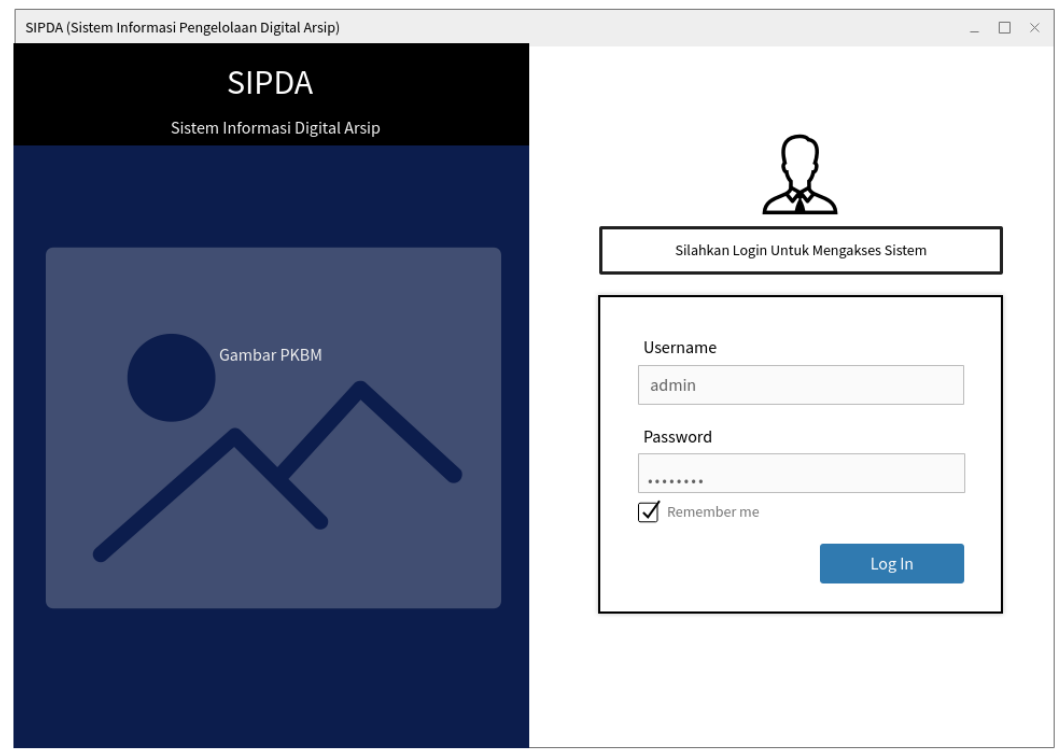

Gambar 3. Tampilan Login

\section{Implementasi Tampilan Menu Pencarian Surat dan Arsip Digital}

Implementasi pencarian surat merupakan tampilan yang digunakan sebagai sebagai tempat mencari surat apakah tersedia dalam sistem atau tidak, berikut tampilan menu pencarian surat pada gambar 6 dibawah ini :

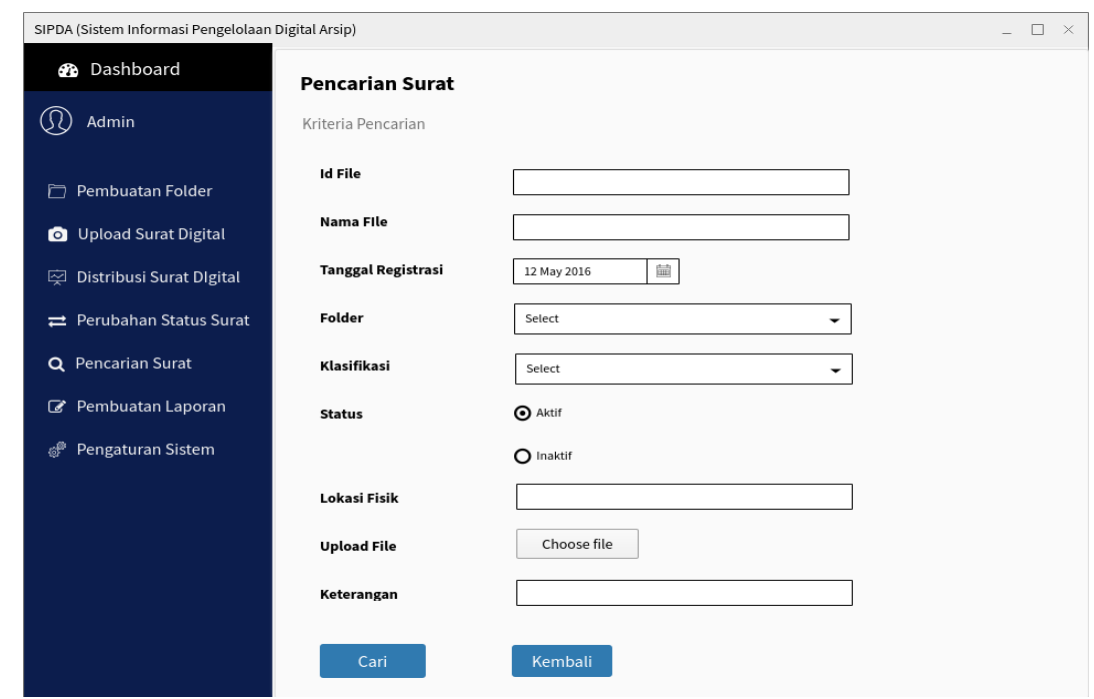

Gambar 4. Tampilan Menu Pencarian Surat 


\section{E. Implementasi Tampilan Menu Distribusi Surat}

Implementasi distribusi surat merupakan tampilan yang digunakan sebagai sebagai menu pendistribusian surat, berikut tampilan menu distribusi surat pada gambar 7 dibawah ini :

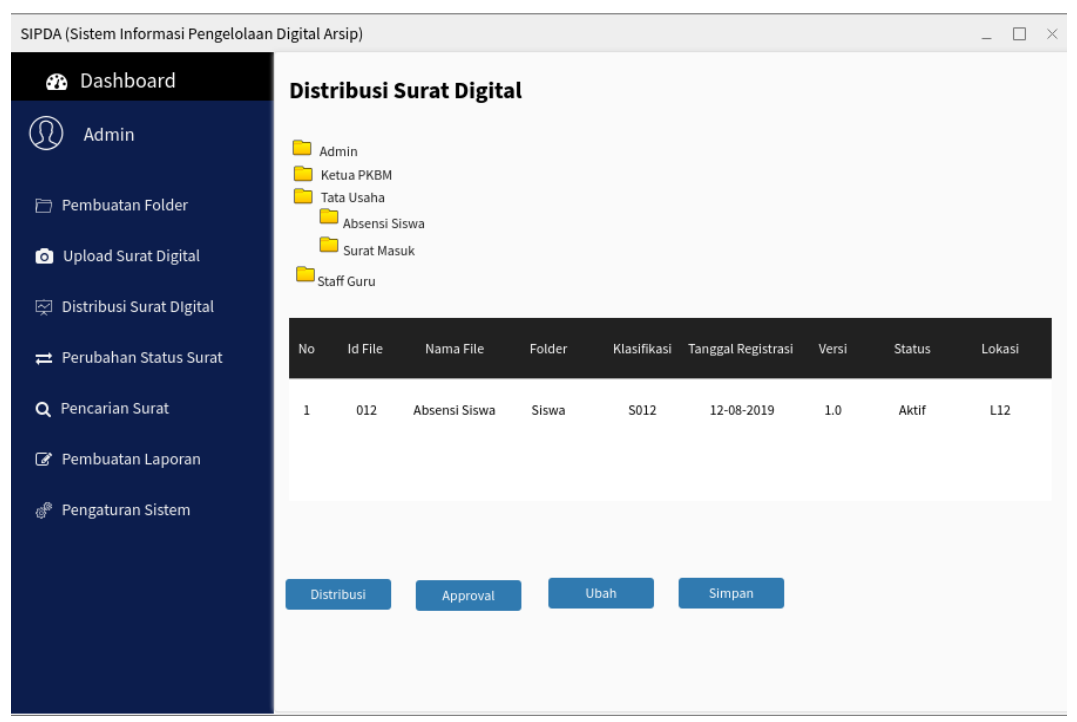

Gambar 5. Tampilan Menu Distribusi Surat

\section{F. Implementasi Tampilan Menu Perubahan Status Surat}

Implementasi distribusi surat merupakan tampilan yang digunakan sebagai sebagai menu perubahan status surat menjadi aktif atau inaktif dan proses pengelolaannya, berikut tampilan menu perubahan status surat pada gambar 8 dibawah ini :

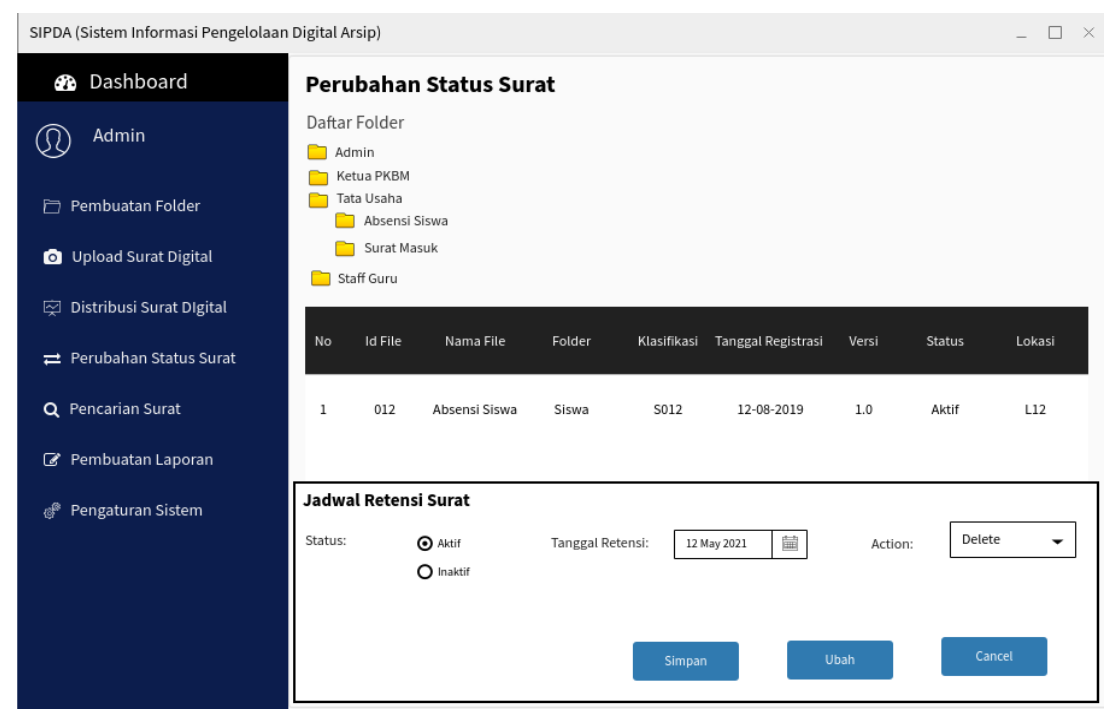

Gambar 7. Tampilan Menu Perubahan Status Surat 


\section{KESIMPULAN}

Berdasarkan hasil penelitian yang telah dilakukan pada PKBM Paja Mandiri Tangerang terhadap permasalahan yang ada mengenai penanganan dokumen aktif, penulis mengambil kesimpulan :

a. Sistem yang saat ini berjalan pada pengolahan surat di PKBM Paja Mandiri Tangerang masih mengunakan pencatatan manual sehingga masih sering adanya kesalahan dalam proses pengelolaan dokumen terutama dalam pengelolaan surat misalkan salah dalam penempatan dokumen fisik, adanya dokumen yang tidak ditemukan kembali serta adanya dokumen yang hilang dalam proses distibusi.

b. Sistem informasi manajemen digital dokumen aktif yang dihasilkan dalam penelitian ini, dirancang dengan harapan dapat membantu PKBM pengembangan sistem pengelolaan dsurat dikemudian hari sehingga proses mengelola surat menjadi efektif dan efisien.

\section{UCAPAN TERIMA KASIH}

Peneliti mengucapkan banyak terima kasih kepada :

1. Bapak M. Kusudirahardjo Sulanjar selaku pendiri PKBM Paja Mandiri Tangerang yang telah memberi ijin untuk melakukan penelitian di PKBM Paja Mandiri

2. Bapak Eko Anjar Rianto selaku Penanggung Jawab PKBM Paja Mandiri atas bantuannya kepada peneliti dalam melakukan penelitian di PKBM Paja Mandiri.

\section{REFERENSI/DAFTAR PUSTAKA}

ANRI. (2015). Undang-Undang Republik Indonesia Nomor 43 Tahun 2009 Tentang Kearsipan dan PP Republik Indonesia Nomor 28 Tahun 2012 tentang Pelaksanaan UU Nomor 43 Tahun 2009 Tentang Kearsipan. P3K ANRI.

Ayub, D., Baheram, M., \& Achmad, S. (2014). Tanggung Jawab Pengelola Pusat Kegiatan Belajar Masyarakat (PKBM) dalam Melaksanakan Kegiatan Pendidikan Nonformal di Kabupaten Rokan Hulu Provinsi Riau. Jurnal Pendidikan Univ Riau, 5(2), 106-114.

Fitriawati, N., Herdiansah, A., \& Gunawan, A. (2019). Sistem Informasi Program Keluarga Harapan Studi Kasus Kecamatan Kosambi Tangerang. Jurnal Teknik Informatika (JIKA) Universitas Muhammadiyah Tangerang, 3(2), 21-26.

Gelinas, J.U; Dull, Richard B; Wheeler, P. R. (2012). Accounting Information Systems (1st ed.). Cengage Learning.

Handayani, T., Herdiansah, A., Hariyani, N., Nugroho, T., \& Informatika, T. (2020). Sistem Informasi Simpan Pinjam Studi Kasus Koperasi Kodanua Serang. Jurnal Teknik Informatika (JIKA) Universitas Muhammadiyah Tangerang, 4(1), 1419.

Herdiansah, A. (2020). Sistem Pendukung Keputusan Referensi Pemilihan Tujuan Jurusan Teknik di Perguruan Tinggi Bagi Siswa Kelas XII IPA Menggunakan Metode AHP. Jurnal MATRIK, 19(2), 223-234. https://doi.org/https://doi.org/10.30812/matrik.v19i2.579

Mustofa, K. (2010). Model Pendidikan dan Pelatihan; Konsep dan Aplikasi (1st ed.). Alfabeta.

Romney, M., \& Steinbart, P. J. (2011). Sistem Informasi Akuntansi (D. Arnos Kwary \& D. Fitriasari (eds.); 9th ed.). Salemba Empat.

Utari D, R., \& Wibowo, A. (2013). Penanganan Arsip Secara Elektronik: Inovasi Bidang Administrasi Perkantoran Dalam Usaha Pelestarian Lingkungan. Seminar Nasional Teknologi Terapan - Sekolah Vokasi UGM, 1(1), 131-135. 